\title{
Microbial Ecology \\ A new species of the $y$-protobacterium Francisella, F. adeliensis sp. nov., endocytobiont in an Antarctic marine ciliate and potential evolutionary forerunner of pathogenic species \\ --Manuscript Draft--
}

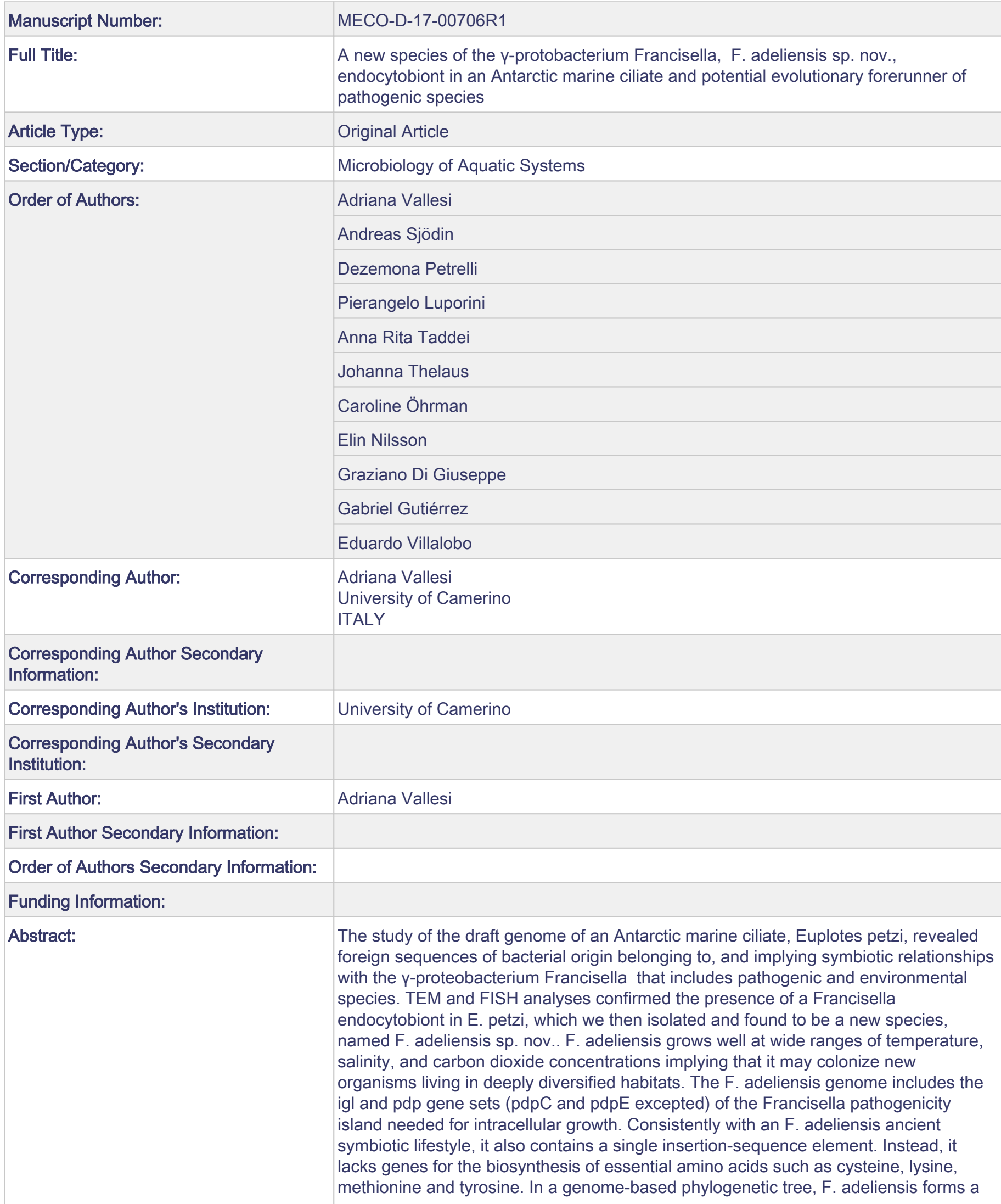




\begin{tabular}{|c|c|}
\hline & $\begin{array}{l}\text { new early branching clade, basal to the evolution of pathogenic species. The } \\
\text { correlations of this clade with the other clades raise doubts about a genuine free-living } \\
\text { nature of the envronmental Francisella species isolated from natural and man-made } \\
\text { environments, and suggest that F. adeliensis should be considered a pioneer in the } \\
\text { Francisella colonization of eukaryotic organisms. }\end{array}$ \\
\hline Response to Reviewers: & $\begin{array}{l}\text { We would like to gratefully acknowledge the Reviewer \#1 for the appreciation of our } \\
\text { work and for the suggestion directed to improve the original version of the manuscript. } \\
\text { According to his/her suggestion, the F adeliensis genome was screened for the } \\
\text { Francisella Pathogenicity Island. Two genes (pdpC and pdpE) were found lacking from } \\
\text { the gene sets encoding the Type VI secretion system, and the implication of this loss } \\
\text { was discussed. } \\
\text { With regard to the comment of Reviewer \#2, we have carried out a TEM analysis to } \\
\text { better visualize the F. adeliensis localization inside the host, and dedicated a new } \\
\text { multi-panel figure to this localization. However, in relation to the Reviewer criticism that } \\
\text { "The authors are using a word of symbiotic against this bacterium [without] confirming } \\
\text { whether this F. adellensis has some mutual functions as the symbiotic bacteria for the } \\
\text { host cell", we need to point out that our manuscript does not deal with } \\
\text { Francisella/Euplotes symbiotic relationships. We did not claim at all about species- } \\
\text { specificity relationships. In fact, in the Discussion section of the manuscript we have } \\
\text { written that "Growing well at temperatures ranging from } 4 \text { to } 30 \text { 'C and promptly } \\
\text { adapting to 0-35 \%o variations in the ambient salinity, F. adeliensis appears capable of } \\
\text { colonizing other organisms independently of their adaptation to live in marine, brackish } \\
\text { or lacustrine habitats of either cold, or temperate areas". We understand and use the } \\
\text { term "symbiosis" (cytobiont) according to the original definition of Heinrich Anton de } \\
\text { Bary (1879): "The living together of unlike organisms". }\end{array}$ \\
\hline
\end{tabular}


endocytobiont in an Antarctic marine ciliate and potential evolutionary forerunner of

5 Adriana Vallesi ${ }^{1 *}$, Andreas Sjödin ${ }^{2,3}$, Dezemona Petrelli ${ }^{1}$, Pierangelo Luporini ${ }^{1}$, Anna Rita Taddei ${ }^{4}$, Johanna

6 Thelaus $^{3}$, Caroline Öhrman ${ }^{3}$, Elin Nilsson ${ }^{3}$, Graziano Di Giuseppe ${ }^{5}$, Gabriel Gutiérrez $^{6}$, Eduardo Villalobo ${ }^{7 *}$.

7

$8{ }^{1}$ School of Biosciences and Veterinary Medicine, University of Camerino, 62032 Camerino (MC), Italy

$9 \quad{ }^{2}$ Department of Chemistry, Computational Life Science Cluster (CLiC), Umeå University, Umeå, Sweden

${ }^{3}$ Division of CBRN Defence and Security, Swedish Defence Research Agency, FOI, Umeå, Sweden

${ }^{4}$ Center of Large Equipment-section of Electron Microscopy, University of Tuscia, Largo dell'Università,

${ }^{5}$ Department of Biology, University of Pisa, 56126 Pisa, Italy

${ }^{6}$ Departamento de Genética, Universidad de Sevilla, Av Reina Mercedes 6, 41012 Seville, Spain

${ }^{7}$ Departamento de Microbiología, Universidad de Sevilla, Av Reina Mercedes 6, 41012 Seville, Spain

* Corresponding authors: Adriana Vallesi, tel: +39 0737403256 Fax: +39 0737403290, e-mail: 


\section{Abstract}

24 The study of the draft genome of an Antarctic marine ciliate, Euplotes petzi, revealed foreign sequences of bacterial origin belonging to, and implying symbiotic relationships with the $\gamma$-proteobacterium Francisella that includes pathogenic and environmental species. TEM and FISH analyses confirmed the presence of a Francisella endocytobiont in E. petzi, which we then isolated and found to be a new species, named $F$. adeliensis sp. nov.. F. adeliensis grows well at wide ranges of temperature, salinity, and carbon dioxide concentrations implying that it may colonize new organisms living in deeply diversified habitats. The $F$. adeliensis genome includes the igl and $p d p$ gene sets ( $p d p C$ and $p d p E$ excepted) of the Francisella pathogenicity island needed for intracellular growth. Consistently with an $F$. adeliensis ancient symbiotic lifestyle, it also contains a single insertion-sequence element. Instead, it lacks genes for the biosynthesis of essential amino acids such as cysteine, lysine, methionine and tyrosine. In a genome-based phylogenetic tree, F. adeliensis forms a new early branching clade, basal to the evolution of pathogenic species. The correlations of this clade with the other clades raise doubts about a genuine free-living nature of the envronmental Francisella species isolated from natural and man-made environments, and suggest that $F$. adeliensis should be considered a pioneer in the Francisella colonization of eukaryotic organisms.

Keywords: endosymbiosis, microbial associations, polar microbiology, environmental Francisella, Francisella phylogeny, Euplotes

\section{Introduction}

43 Like their multicellular descendants, also single-celled eukaryotes host a huge variety of bacteria. Ciliates in particular are a preferential and stable home to bacteria, which may be carried either attached as epibionts to the cell body surface, as is the case of the association between a group (designated as 'epixenosomes') of Verrucomicrobia and Euplotidium itoi [1], or enclosed as endocytobionts inside the cell body. Being a principal component of the diet of ciliates, that are mostly phagotrophic and filter-feeding, bacteria can easily escape digestion and adopt a new intracellular lifestyle [2]. Roughly 250 ciliate species, among the nearly 10,000 that are in total known, have been detected to be hosts of endocytobiont bacteria. Large-size species of Paramecium, Euplotes and Spirostomum may be home also of mixed populations of unrelated species of bacteria $[3,4]$. 

species of Holospora and Caedibacter, that are colonizers of the nuclear apparatus of freshwater species of Paramecium $[5,6]$. These symbionts have been successfully isolated from host-cell homogenates, but any attempt of cultivation outside their hosts has failed as in the case of any other bacterial symbiont of aerobic ciliates [7].

A substantial contribution to improve this knowledge may now be provided by the isolation and cultivation of Francisella bacteria living as endocytobionts in marine species of Euplotes, a genus which is quite rich also in freshwater species extensively studied for their symbiotic associations with polymorphic populations of Polynucleobacter [8]. F. endociliophora, earlier described as a novel subspecies of $F$. noatunensis [9], is the first Francisella that has been isolated and genome-sequenced from a marine species of Euplotes, E. raikovi, dwelling in temperate waters [10]. Here we report the isolation and genome sequencing of another new species of Francisella, F. adeliensis sp. nov., living as endocytobiont in a bipolar (Antarctic and Arctic) species of Euplotes, E. petzi. intracellular pathogen of both invertebrate and vertebrate hosts, human beings included [13, 14]. $F$. this genus.

\section{Materials and Methods}

\section{E. petzi cultures}

The E. petzi cells were isolated from a sample of seawater and sandy bottom collected by means of a sediment trap from Adelie Cove in Antarctica, at a depth of $27 \mathrm{~m}$, a temperature of $-1.2^{\circ} \mathrm{C}$ and a salinity of 
light and $12 \mathrm{~h}$ of dark, as previously described [21]. The green alga Dunaliella tertiolecta was used as food source.

\section{Fluorescent in situ hybridization (FISH)}

E. petzi cells were collected from severely starved cultures, transferred onto glass slides, fixed with $4 \%$ formaldehyde in phosphate saline buffer (PBS) for $10 \mathrm{~min}$ at room temperature, and permeabilized by ethanol gradient $(50 \%, 80 \%$ and $100 \%$ of ethanol in water, for $10 \mathrm{~min}$ each). The fluorescein-labeled probe EUB338 (5'-GCTGCCTCCCGTAGGAT-3') for eubacteria and the Cy3-labeled probe Bwall1448 (5'CAACCATTCGCCGGGCCT-3’) for Francisella were synthesized by Integrated DNA Technologies (Coralville, Iowa, USA). Hybridization was performed following the method described by Hugenholtz et al. [22]. Briefly, $2 \mu \mathrm{l}$ of each probe solution $(50 \mathrm{ng} / \mu \mathrm{l})$ in $20 \mu \mathrm{l}$ hybridization buffer $(0.9 \mathrm{M} \mathrm{NaCl}, 20 \mathrm{mM}$ Tris$\mathrm{HCl} \mathrm{pH} 7.0,15 \%$ formamide, $0,1 \%$ SDS) were added directly to the cells on slides. Hybridization was performed in a humid chamber at $46^{\circ} \mathrm{C}$ for $3 \mathrm{~h}$. Slides were then washed 20 min with washing buffer (318 $\mathrm{mM} \mathrm{NaCl}, 20 \mathrm{mM}$ Tris- $\mathrm{HCl} \mathrm{pH}$ 7.0, $0.1 \%$ SDS) at $48{ }^{\circ} \mathrm{C}$ and air dried. Slides were embedded with antifading mounting medium and then inspected with a Nikon confocal microscope (Nikon, Amsterdam, The Netherlands).

Trasmission electron microscopy (TEM)

For TEM analyses, samples were fixed with $2.5 \%$ glutaraldehyde and $6 \%$ sucrose in $0.1 \mathrm{M}$ cacodylate buffer, $\mathrm{pH} 7.2$, for $2 \mathrm{~h}$ at $4{ }^{\circ} \mathrm{C}$. After three washings at $4{ }^{\circ} \mathrm{C}$ in the same buffer, samples were post-fixed with $1 \%$ osmium tetroxide in $0.1 \mathrm{M}$ cacodylate buffer, $\mathrm{pH} 7.2$, for $1 \mathrm{~h}$ at $4^{\circ} \mathrm{C}$, washed in the same buffer, and dehydrated in a gradient ethanol series. Samples were then infiltrated with mixtures of LRWhite resin/ethanol in different percentages, embedded in pure LRWhite resin, and left to polymerize for 2 days at $50^{\circ} \mathrm{C}$. Resin blocks were cut with a Reichert Ultracut ultramicrotome using a diamond knife. Ultrathin sections (60-80 nm) were collected on copper grids, stained with uranyl acetate and lead citrate, and observed with a JEOL 1200 EXII electron microscope. Micrographs were captured using an Olympus SIS VELETA CCD camera equipped with iTEM software.

\section{Isolation, identification and culturing}


F. adeliensis was isolated from E. petzi following the protocol of Sjödin et al. [10]. Briefly, E. petzi cell samples were bead beaten and acid treated according to Humrighouse et al. [23], before being diluted in PBS and spread on CHAB (Cysteine Heart Agar Blood) culture plates, supplemented with $10^{5} \mathrm{U} / \mathrm{l}$ penicillin and $40 \mathrm{mg} / \mathrm{l}$ vancomycin as described [24]. The culture plates were incubated at $4{ }^{\circ} \mathrm{C}$ for 1 to 2 weeks and monitored for bacterial growth. Colonies were then isolated and maintained in $\mathrm{CHAB}$ plates at $4{ }^{\circ} \mathrm{C}$. To identify F. adeliensis from other contaminating bacteria, isolated colonies were picked, resuspended in $20 \mu \mathrm{l}$ of water and immediately lysed by boiling for 3 min. Five $\mu$ of each lysed cell suspension were used as template in PCR, run using two sets of primers: fw1 (5'-GCGTTTACCACGGAGTGATT-3') and rv1 (5'TGGAGCCTAGCGGGATC-3'); fw2 (5'-AGTCAGGGAGGAAGTTTATTTGGTT-3') and rv2 (5'CACCTTCCTCCGCCTTGT-3'). Positive clones were maintained in CHAB plates for subsequent analysis. Five $\mu \mathrm{l}$ of serial dilution of the Francisella suspension were spotted on CHAB plates and incubated at 4, 12, 20,30 and $37{ }^{\circ} \mathrm{C}$. Plates were checked for bacterial growth every 3 days. For growth assays in liquid medium, an overnight culture was used to inoculate aliquots of $50 \mathrm{ml}$ of $\mathrm{T}$ medium [25] to reach an $\mathrm{OD}_{600}$ ranging from 0.01 to 0.05 . Flasks were then incubated at different temperatures, salinity and $\mathrm{CO}_{2}$ concentrations. Bacterial growth was monitored by measuring the $\mathrm{OD}_{600}$ every day during the first week, then every three days. The number of generation/day were calculated using the Origin 8 software. and an oxidase-strip (OXOID- Thermo Fisher Scientific Inc, Monza, Italy), respectively. Motility was determined with the hanging drop technique.

\section{Genome sequencing and assembly}

Isolated DNA were sequenced using Nextera XT library protocol on an Illumina MiSeq instruments in addition to a Pacific Biosciences RSII system (10-kb library, 2-h movie length), generating a total of 57,926 PacBio reads with an average read length of 11,653 bp, using a single-molecular real-time (SMRT) cells. version 2.3.0. Polishing of the draft genome was performed using Illumina reads in berokka and Pilon [26].

\section{Phylogenetic analysis}


The phylogenetic analysis was inferred using the Neighbor-Joining method [27]. The evolutionary distances among Francisella genomes were computed using the number of differences method [28] and are in the units of the number of base differences per sequence. The analysis involved 139 nucleotide sequences, with a total of 213,734 positions in the final dataset. Positions containing gaps and missing data were eliminated.

Evolutionary analyses were conducted in MEGA7 [29]. Fangia hongkongensis was included as outgroup to generate the genome-based phylogenetic tree.

\section{Results}

\section{Identification}

Total DNA preparations of $E$. petzi subjected to high throughput sequencing generated 24,800 assembled contigs (Villalobo and Vallesi, unpublished), of which approximately 800 (equivalent to a total of $1.6 \mathrm{Mb}$ ) revealed a close similarity to bacterial sequences available from public databases, with the highest matching value of each contig systematically resulting against gene sequences of Francisella species.

Among the 800 contigs, one of 5091 bp included the 16S and 23S rRNA gene sequences plus the sequences of the tRNA ${ }^{\text {Ile }}$ and tRNA ${ }^{\text {Ala }}$ genes (Fig. 1A). Therefore, it revealed to be a typical bacterial rDNA operon. Using the SILVA INcremental Aligner bioinformatics tool [30], the 16S rRNA gene sequence of this operon was classified as belonging to Francisella with $94.39 \%$ identity and 97 score along 1,480 bp. Given that the $3 \%$ cut-off rule [31] for a $16 \mathrm{~S}$ divergence among species was fulfilled, the new 16S rRNA gene sequence was assumed to belong to a new Francisella species for which the proposed name is Francisella adeliensis nov. sp.. The species name is after that of the Antarctic cove, Adelie, from which E. petzi, the $F$. adeliensis host, was collected.

Analysed in the BLASTN 2.6.1 database [32] for its closest identity, the $F$. adeliensis 16S rRNA gene sequence showed the best alignment (only seven nucleotide variations along $1376 \mathrm{bp}$ ) with the $16 \mathrm{~S}$ gene sequence of an unnamed and uncultured $\gamma$-proteobacterium reported to be a chemoautotrophic symbiont on gills of deep-sea clams and mussels collected at a 10-m depth from the fjord of Saanich Inlet, British Columbia [33]. The other two closest counterparts were the $16 \mathrm{~S}$ sequences of $F$. endociliophora [10] and $F$. salina [24], with $96 \%$ of sequence identity along the 1481-bp gene length.

\section{Intracellular localization}


To verify whether $F$. adeliensis resides as endosymbiont inside $E$. petzi, or it coexists as environmental bacteria with $E$. petzi in culture, E. petzi cells were starved for 10 days to avoid any possible bacterial contamination from undigested food, and analyzed by fluorescent in-situ hybridization (FISH) with two distinct probes: one ('EUB338', see Materials and Methods) specific to a 16S rRNA-sequence conserved in most bacterial species, and the second ('Bwall1448') specific to a 23S rRNA region unique to Francisella [34]. Both probes generated fluorescent signals within the cytoplasm of E. petzi cells (Fig. 1B), and their colocalization provided evidence that $F$. adeliensis was the only guest.

Transmission electron microscopy of E. petzi cells (deprived of food for not less than one week before being used) confirmed the presence of numerous bacteria (Fig. 2). Only occasionally were they observed to be individually dispersed in the cytoplasm. Each bacterium was confined inside a membranous-bound vesicle (Fig. 2F,G), or it was apparently free in the cytosol (Fig. 2E). Much more often, however, bacteria appeared clustered together in larger fusogenic membrane-bound structures (Fig. C,D), which were quite heterogeneous in size and number of enclosed bacteria, and were usually located in close proximity of the host's somatic and transcriptionally active nucleus (macronucleus).

\section{Phenotypic traits}

The isolation of $F$. adeliensis was carried out from E. petzi cell lysates following the procedure previously used for F. endociliophora [10], taking care to incubate plates at $4{ }^{\circ} \mathrm{C}$. Individual colonies were screened by PCR using two sets of specific primers (Fig. 1A). Primers ('fw1' and 'rv1', see Materials and Methods) of one set were designed to amplify a 360-bp fragment containing a 33-bp sequence lying between the two tRNA coding regions and without counterparts in the rDNA operons of other Francisella species. Primers ('fw2' and 'rv2') of the second set were designed to amplify a 660-bp fragment of the 16S rRNA coding region shared among other Francisella species. Products sequenced from both amplifications showed to fully match the genomic data, confirming the taxonomic identity of the isolated colonies with $F$. adeliensis.

On CHAB plates, F. adeliensis colonies look round, white, and slightly mucoidal, formed by rod-shaped and Gram-negative bacteria that are catalase-positive, oxidase-negative, and non-motile. In solid medium, they are visible after 3 days of incubation at temperatures ranging from 20 to $30{ }^{\circ} \mathrm{C}$, and require $6-12$ days to grow when incubated at 4 and $10{ }^{\circ} \mathrm{C}$ (Fig. 3A). In liquid medium, the highest growth rate was measured at 20 and $30{ }^{\circ} \mathrm{C}$, and the lower at $4{ }^{\circ} \mathrm{C}$ (Fig. 3B). The mean numbers of generations/day were counted to be 
$0.11,0.29,0.53,0.47$ at $4,10,20$ and $30^{\circ} \mathrm{C}$, respectively, and no growth was observed at $37^{\circ} \mathrm{C}$. Roughly one half of bacteria inoculated on plates at $37{ }^{\circ} \mathrm{C}$ died after $16 \mathrm{~h}$ of incubation and none survived after $48 \mathrm{~h}$. In the presence of $5 \% \mathrm{CO}_{2}, F$. adeliensis cultures grew with $\mathrm{OD}_{600}$ values approximately $60 \%$ lower than those measured in ambient atmosphere $(0.04 \%)$. Instead, no significant variation in the growth rate was observed in cultures left to grow in liquid medium containing salt concentrations ranging from 0 to $35 \%$, implying that $F$. adeliensis is a strongly euryhaline bacterium (data not shown).

\section{Genomic features}

The $F$. adeliensis genome extends for 2,054,094 bp, a length matching the mean genome size of other Francisella species $(1.96 \pm 0.14 \mathrm{Mbp}$, Table 1) much more closely than the size of any other bacterial genome (3.82 $\pm 1.8 \mathrm{Mbp}$ ) [35]. It contains 1,880 protein coding sequences, 38 tRNA genes, 10 rRNA genes (four 5S rRNA, three 16S rRNA and three 23S rRNA) and one tmRNA gene (Table 1). Its average nucleotide identity (ANI) with the closest Francisella genomes is in the range of 77-78.8 \% (Table 2), that is distant from the 95-96\% range usually taken as the minimum threshold value to consider two genome sequences as belonging to the same species [36]. Consistently with an intracellular lifestyle, the average $32.6 \% \mathrm{G}+\mathrm{C}$ content of the $F$. adeliensis genome closely reflects the $32.38 \pm 0.24 \%$ content of the other endosymbiotic Francisella, and is significantly lower than the average $\mathrm{G}+\mathrm{C}$ content $(49.1 \pm 12.4 \%)$ shown by free-living bacteria [35].

$$
\text { Based on a search for transposable elements and phages carried out with PHASTER and ISFinder }
$$
softwares [37, 38], the $F$. adeliensis genome contains prophage sequences like other Francisella. However, it includes only one ISFtu4 insertion sequence element (E-value $\left.1 \mathrm{e}^{-15}\right)$.

Analysis of the F. adeliensis genome for the presence of the igl (intracellular growth locus) and $p d p$ (pathogenicity determinant proteins) genes, components of the so-called 'Francisella pathogenicity island' responsible for the virulence of $F$. turalensis $[39,40]$, indicated that all ten igl genes were present, but that the five $p d p$ gene set lacked the $p d p C$ and $p d p E$ genes.

The observation that $F$. adeliensis requires complex media to grow in culture suggested a loss of genes responsible for the synthesis of essential amino acids. This hypothesis was verified by screening the $F$. adeliensis genome for the presence of genes responsible for the synthesis of arginine, cysteine, histidine, lysine, methionine and tyrosine for which the pathogenic F. tularensis is known to be auxotrophic [41]. Only the histidine and arginine biosynthesis appeared to be genetically supported, the histidine biosynthesis by the 
complete set of relevant genes and the arginine biosynthesis by the activity of an argJ gene that likely replaces the lack of $\arg A, \arg D$ and $\arg E$ genes [42]. Instead, the biosynthesis of the other four amino acids appeared genetically not supported. The $F$. adeliensis genome lacks the genes $\operatorname{dapD,} \operatorname{dap} C$ and $\operatorname{dapE}$ encoding enzymes responsible for the lysine biosynthesis [43], as well as the gene encoding cystathionine $\gamma$ synthase responsible for the methionine and cysteine biosynthesis [44]. With regard to the tyrosine biosynthesis, the genome contains the complete gene set for the shikimate pathway, but it lacks the gene encoding prephenate dehydrogenase which converts prephenic acid to 4-hydroxyphenyl-pyruvic acid [45]. In conclusion, $F$. adeliensis shows to be prototrophic for arginine and histidine, and auxotrophic for cysteine, lysine, methionine and tyrosine.

\section{Phylogenetic relationships}

To assess the $F$. adeliensis interspecific relationships, the $F$. adeliensis genome was compared with the other Francisella genomes available from NCBI using 139 gene sequences for a total of 213,734 nucleotide positions. As shown in Fig. 4, F. adeliensis forms its own clade with a high statistical support. Together with the clade formed by $F$. frigiditurris, a species recently isolated from the water of a cooling tower [46], it precedes the split of four other major clades in which all the other Francisella species are subdivided in full accord with the recently proposed genome-based Francisella phylogeny $[46,47]$. One of the four clades is specific to species, such as $F$. tulariensis and $F$. novicida, that are pathogenic to terrestrial hosts, and $F$. persica (formerly Wolbachia persica) isolated from ticks [12, 17]. The second one includes species such as $F$. noatuniensis that are pathogenic to fish, as well as $F$. salina isolated from a seawater sample [46]. The third one includes species such as F. endociliophora and F. halioticida isolated from marine hosts, together with $F$. uliginis isolated from a seawater sample [9, 12, 46]. And the fourth one is specific to Francisella species that have been isolated from waters of cooling systems, and are usually described as 'environmental' species and regarded as belonging to the genus Allofrancisella [48, 49].

\section{Discussion}

The isolation reported here of $F$. adeliensis from an Antarctic strain of E. petzi follows the isolation of $F$. endociliophora from E. raikovi [10], which is a species distributed in the Caspian and Mediterranean Seas and Eastern Atlantic Ocean [50], and the identification of DNA sequences of a taxonomically undetermined Francisella in the genome of E. focardii [51], which is a species endemic to Antarctic coastal waters [52]. 
Altogether these findings strongly suggest that Francisella/Euplotes associations are relatively common in the marine environment, and two additional considerations reinforce this hypothesis. The first consideration is related to the bipolar biogeographic distribution that characterizes the species structure of the $F$. adeliensis's host, E. petzi [21, 53]. Embracing Arctic and White Sea populations in addition to Antarctic and peri-Antarctic ones, this distribution clearly implies that the $F$. adelinesis association with $E$. petzi is likely not restrained to the Antarctic waters where it has been detected. Being extended to the high latitudes of both the hemispheres, it appears to be virtually global and the analysis of other bipolar Euplotes species for their symbiotic associations with $F$. adeliensis and/or its close relatives may definitively establish these global dimensions. The second and more significant consideration is related to the psychrophilic and euryhaline behaviour shown by $F$. adeliensis. Growing well at temperatures ranging from 4 to $30^{\circ} \mathrm{C}$ and promptly adapting to 0-35\% variations in the ambient salinity, $F$. adeliensis appears capable of colonizing other organisms independently of their adaptation to live in marine, brackish or lacustrine habitats of either cold, or temperate areas.

The 16S rRNA gene sequences are the molecules of choice for phylogenetic reconstructions, but their use in devising a Francisella phylogenetic tree has frequently been biased by branches supported by low bootstrap values due to the particularly high degree of conservation that these sequences show in Francisella. Only the recent availability of genomic data provided more solid grounds to trace the phylogenetic relationships among Francisella species, producing phylogenetic trees with more solid statistic support $[46,54]$. In the genome-based tree updated with the inclusion of $F$. adeliensis (shown above in Fig. 2), F. adeliensis branches surprisingly distant from all the intracellular Francisella, including $F$. endociliophora endocytobiont in E. raikovi. It correlates much closer to the two earliest branching clades that are uniquely formed by Francisella species, namely $F$. frigiditurris, Allofrancisella frigididaquae and $A$. guangzhouensis, isolated from cooling towers. As such, they are collectively regarded as environmental species.

Granted that these species are really free living - considering the strong acidic conditions used for their isolation, it cannot be excluded that they have actually been isolated from some eukaryotic microorganisms living inside the cooling towers-this correlation implies that $F$. adeliensis foreruns the Francisella adaptive evolution in replacing a free-living lifestyle with an intracellular/endosymbiotic style. And the $F$. adeliensis acquisition of the endosymbiotic lifestyle is likely to be quite ancient, considering that a single IS element is present in its genome. In effect, a low number of mobile genetic elements is widely accepted to be a 
287

288

289

290

291

292

293

294

295

296

297

298

299

300

301

302

303

304

305

306

307

308

309

310

311

312

313

314

315

316

distinctive trait of an ancient stage of intracellular life and an expansion of these elements to be distinctive of initial stages of host restriction $[55,56]$. In addition, the finding that $F$. adeliensis is auxotrophic for cysteine, lysine, methionine and threonine, and likely depends on the host for nutrient supply, establishes a close physiological analogy with pathogenic strains of $F$. tularensis, whose virulence depends on the activity of the Francisella pathogenicity island cluster of genes [40]. In a mouse model of tularaemia, it has been shown that among these genes $F$. tularensis and $F$. novicida particularly need the expression the $p d p C$ gene in order to escape from phagosomes and become free in the cytosol [57]. Neither the $p d p E$ gene, which is not directly involved in $F$. tularensis virulence, nor the $p d p C$ gene were identified in the $F$. adeliensis genome. In spite of this gene loss, however, evidence from TEM analysis indicates that, in addition to more common fusogenic membrane-bound structures closely recalling the "Francisella containing vacuoles" involved in the autophagy-mediated mechanism of $F$. tularensis re-entry into the endocytic compartment [58], F. adeliensis may produce cytosolic stages. Although these stages might suggest that $F$. adeliensis is a potential ecological reservoir for the evolution of pathogenic Francisella, the observation that it is unable to proliferate at $37^{\circ} \mathrm{C}$ should rule out any ability to colonize and be harmful to homothermic, warm-blood organisms.

\section{Description of Francisella adeliensis sp. nov.}

Francisella adeliensis (a.de.lien'sis. L. adj. of Adelie) is named after Adelie Cove, the location in Antarctica where the host, the ciliate Euplotes petzi, was collected in 2005 [21]. The type strain is deposited at the Swedish Defence Research Institute (FOI), Francisella strain collection \# FSC1327. Within its host, F. adeliensis resides in the cytoplasm, as determined by transmission electron microscopy and a FISH analysis carried out with the Francisella-specific probe Bwall1448 [34]. Cells are Gram-negative, non-motile, catalase-positive, oxidase-negative and grow at a wide range of temperature $\left(4-30^{\circ} \mathrm{C}\right)$, salinity $(0-35 \%$ ), and carbon dioxide concentrations $(0.04-5 \%)$. The $F$. adeliensis complete genome sequence is available at GenBank, with the accession number CP021781, and supporting sequencing data are deposited in Bioproject PRJNA389235.

\section{Acknowledgements}

This work was supported by the PNRA (Programma Nazionale di Ricerca in Antartide) from the Italian Ministry of Research (MIUR), FAR (Fondo Ateneo Ricerca) from the University of Camerino, by the 

supported by the Universidad de Sevilla (Movilidad Docente ERASMUS). We acknowledge the National Genomics Infrastructure (NGI)/Uppsala Genome Center and UPPMAX for providing assistance in massive parallel sequencing and computational infrastructure. The work performed at NGI/Uppsala Genome Center was funded by RFI/VR and Science for Life Laboratory, Sweden.

Conflict of Interest The authors declare that they have no conflict of interest.

\section{References}

1. Petroni G, Spring S, Schleifer KH, Verni F, Rosati G (2000) Defensive extrusive ectosymbionts of Euplotidium (Ciliophora) that contain microtubule-like structures are bacteria related to Verrucomicrobia. Proc Natl Acad Sci USA 97:1813-1817

2. Görtz HD (2006) Symbiotic Associations Between Ciliates and Prokaryotes In: Dworkin M, Falkow S, Rosenberg E, Schleifer K-H, Stackebrandt E (eds) The Prokaryotes, Springer, New York, pp 364-402

3. Fokin SI (2012) Frequency and biodiversity of symbionts in representatives of the main classes of Ciliophora. Eur J Protistol 48:138-148

4. Dziallas C, Allgaier M, Monaghan MT, Grossart HP (2012) Act together-implications of symbioses in aquatic ciliates. Front microbiol 3:288

5. Fujishima M, Görtz H-D (1983) Infection of macronuclear anlagen of Paramecium caudatum with the macronucleus-specific symbiont Holospora obtusa. J Cell Sci 64:137-146

6. Fujishima M (2009) Infection and maintenance of Holospora species in Paramecium caudatum. In: Fujishima M (ed) Endosymbionts in Paramecium, Springer, Dordrecht Heidelberg London New York, pp 201-226

7. Schweikert M, Fujishima M, Görtz HD (2013) Symbiotic associations between ciliates and prokaryotes. In: Rosenberg E, DeLong EF, Lory S, Stackebrandt E, Thompson F (eds) The Prokaryotes: prokaryotic biology and symbiotic associations, Springer, Berlin, Heidelberg: pp $427-$ 463

8. Vannini C, Ferrantini F, Ristori A, Verni F, Petroni G (2012) Betaproteobacterial symbionts of the ciliate Euplotes: origin and tangled evolutionary path of an obligate microbial association. Environ Microbiol 14:2553-2563

9. Schrallhammer M, Schweikert M, Vallesi A, Verni F, Petroni G (2011) Detection of a novel subspecies of Francisella noatunensis as endosymbiont of the ciliate Euplotes raikovi. Microbial Ecol 61: 455-464

10. Sjödin A, Öhrman C, Bäckman S, Lärkeryd A, Granberg M, Lundmark E, et al (2014) Complete genome sequence of Francisella endociliophora strain FSC1006 isolated from a laboratory culture of the marine ciliate Euplotes raikovi. GenomeA 2:e01227-14

11. Sjöstedt A (2005) Family III Francisellaceae fam nov. In: Garrity GM (ed) Bergeys Manual of Systematic Bacteriology, Springer, Baltimore USA: pp 199-210

12. Colquhoun DJ, Larsson P, Duodu S, Forsman M (2014) The family Francisellaceae In: Rosenberg E, DeLong EF, Lory S, Stackebrandt E, Thompson F (eds) The Prokaryotes, Springer, Berlin Heidelberg, pp 287-314

13. Dorofe'ev KA (1947) Classification of the causative agent of tularemia. Symposium Research Works Institute Epidemiology and Microbiology Chita 1:170-180

14. Olsufjev NG, Meshcheryakova IS (1983) Subspecific taxonomy of Francisella tularensis McCoy and Chapin 1912. Int J Syst Bacteriol 33:872-874 
15. Ottem KF, Nylund A, Karlsbakk E, Friis-Moller A, Kamaishi T (2009) Elevation of Francisella philomiragia subsp noatunensis Mikalsen et al (2007) to Francisella noatunensis comb nov [syn Francisella piscicida Ottem et al (2008) syn nov] and characterization of Francisella noatunensis subsp orientalis subsp nov two important fish pathogens. J Appl Microbiol 106:12311243

16. Colquhoun DJ, Duodu S (2011) Francisella infections in farmed and wild aquatic organisms. Vet Res 8:42:47

17. Larson MA, Nalbantoglu U, Sayood K, Zentz EB, Cer RZ, Iwen PC, et al (2016) Reclassification of Wolbachia persica as Francisella persica comb nov and emended description of the family Francisellaceae. Int J Syst Evol Microbiol 66:1200-1205

18. Hollis DG, Weaver RE, Steigerwalt AG, Wenger JD, Moss CW, Brenner DJ (1989) Francisella philomiragia comb nov (formerly Yersinia philomiragia) and Francisella tularensis biogroup novicida (formerly Francisella novicida) associated with human disease. J Clin Microbiol 27:16011608

19. Mailman TL, Schmidt MH (2005) Francisella philomiragia adenitis and pulmonary nodules in a child with chronic granulomatous disease. Can J Infect Dis Med Microbiol 16:245-248

20. Sjöstedt A (2007) Tularemia: history epidemiology pathogen physiology and clinical manifestations. Ann N Y Acad Sci 1105:1-29

21. Di Giuseppe G, Erra F, Frontini F, Dini F, Vallesi A, Luporini P (2014) Improved description of the bipolar ciliate Euplotes petzi and definition of its basal position in the Euplotes phylogenetic tree, Eur J Protistol 50:402-411

22. Hugenholtz P, Tyson GW, Blackall LL (2002) Design and evaluation of 16S rRNA-targeted oligonucleotide probes for fluorescence in situ hybridization. Methods Mol Biol 179:29-42

23. Humrighouse BW, Adcock NJ, Rice EW (2011) Use of acid treatment and a selective medium to enhance the recovery of Francisella tularensis from water. Appl Environ Microbiol 77:6729-6732

24. Petersen JM, Carlson J, Yockey B, Pillai S, Kuske C, Garbalena G, et al (2009) Direct isolation of Francisella spp from environmental samples. Lett Appl Microbiol 48:663-667

25. Pavlovich NV, Mishan'kin BN (1987) Transparent nutrient medium for culturing Francisella tularensis. Antibiot Med Biotekhnol 32:133-137

26. Walker BJ, Abeel T, Shea T, Priest M, Abouelliel A, Sakthikumar S, et al (2014) Pilon: an integrated tool for comprehensive microbial variant detection and genome assembly improvement. PloS one 9:e112963

27. Saitou N, Nei M (1987) The neighbor-joining method: A new method for reconstructing phylogenetic trees. Mol Biol Evol 4:406-425

28. Nei M, Kumar S (2000) Molecular Evolution and Phylogenetics. Oxford University Press, New York

29. Kumar S, Stecher G, Tamura K (2016) MEGA7: Molecular Evolutionary Genetics Analysis version 70 for bigger datasets. Mol Biol Evol 33:1870-1874

30. Pruesse E, Peplies J, Glöckne FO (2012) SINA: accurate high-throughput multiple sequence alignment of ribosomal RNA genes. Bioinformatics 28:1823-1829

31. Kim M, Oh HS, Park SC, Chun J (2014) Towards a taxonomic coherence between average nucleotide identity and 16S rRNA gene sequence similarity for species demarcation of prokaryotes. Int J Syst Evol Microbiol 64:346-351

32. Morgulis A, Coulouris G, Raytselis Y, Madden TL, Agarwala R, Schäffer AA (2008) Database indexing for production MegaBLAST searches. Bioinformatics 24:1757-1764

33. Walsh DA, Zaikova E, Howes CG, Song YC, Wright JJ, Tringe SG, et al (2009) Metagenome of a versatile chemolithoautotroph from expanding oceanic dead zones. Science 326:578-582

34. Splettstoesser WD, Seibold E, Zeman E, Trebesius K, Podbielski A (2010) Rapid differentiation of Francisella species and subspecies by fluorescent in situ hybridization targeting the $23 \mathrm{~S}$ rRNA. BMC Microbiol 10:72

35. Merhej V, Royer-Carenzi M, Pontarotti P, Raoult D (2009) Massive comparative genomic analysis reveals convergent evolution of specialized bacteria. Biol Direct 4:13

36. Stackebrandt E, Ebers J (2006) Taxonomic parameters revisited: tarnished gold standards. Microbiol Today 33:152-155

37. Arndt D, Grant JR, Marcu A, Sajed T, Pon A, Liang Y, Wishart DS (2016) PHASTER: a better faster version of the PHAST phage search tool. Nucl Acids Res 44:W16-W21

38. Siguier P, Pérochon J, Lestrade L, Mahillon J, Chandler M (2006) ISfinder: the reference centre for bacterial insertion sequences. Nucl Acids Res 34:D32-D36

39. Gray CG, Cowley SC, Cheung KK, Nano FE (2002) The identification of five genetic loci of Francisella novicida associated with intracellular growth. FEMS Microbiol Lett 215:53-56 
40. Nano FE, Zhang N, Cowley SC, Klose KE, Cheung KK, Roberts MJ, Ludu JS, Letendre GW, Meierovics AI, Stephens G, Elkins KL (2004) A Francisella tularensis pathogenicity island required for intramacrophage growth. J Bacteriol 186: 430-6436

41. Santic M, Abu Kwaik Y (2013) Nutritional virulence of Francisella tularensis. Front Cell Infect Microbiol 3:112

42. Xu Y, Labedan B, Glansdorff N (2007) Surprising arginine biosynthesis: a reappraisal of the enzymology and evolution of the pathway in microorganisms. Microbiol Mol Biol Rev 71:36-47

43. Velasco AM, Leguina JI, Lazcano A (2002) Molecular evolution of the lysine biosynthetic pathways. J Mol Evol 55:445-449

44. Ferla MP, Patrick WM (2014) Bacterial methionine biosynthesis. Microbiology 160: 1571-1584

45. Ahmad S, Jensen RA (1988) The phylogenetic origin of the bifunctional tyrosine-pathway protein in the enteric lineage of bacteria. Curr Microbiol 16:295-310

46. Challacombe JF, Petersen JM, Hodge D, Pillai S, Kuske CR (2017) Whole-genome relationships among Francisella bacteria of diverse origins define new species and provide specific regions for detection. Appl Environ Microbiol 83: e02589-16

47. Sjödin A, Svensson K, Öhrman C, Ahlinder J, Lindgren P, Duodu S, et al (2012) Genome characterisation of the genus Francisella reveals insight into similar evolutionary paths in pathogens of mammals and fish. BMC Genomics 13:268

48. Qu PH, Chen SY, Scholz HC, Busse HJ, Gu Q, Kämpfer P, et al (2013) Francisella guangzhouensis sp nov isolated from air conditioning systems. Int J Syst Evol Microbiol 63:36283635

49. Qu PH, Li Y, Salam N, Chen SY, Liu L, Gu Q, et al (2016) Allofrancisella inopinata gen nov sp nov and Allofrancisella frigidaquae sp nov isolated from water-cooling systems and transfer of Francisella guangzhouensis Qu et al 2013 to the new genus as Allofrancisella guangzhouensis comb nov. Int J Syst Evol Microbiol 66:4832-4838

50. Jiang J, Zhang Q, Warren A, Al-Rasheid KA, Song W (2010) Morphology and SSU rRNA genebased phylogeny of two marine Euplotes species E orientalis spec nov and E raikovi (Ciliophora Euplotida). Eur J Protistol 46:121-132

51. Pucciarelli S, Devaraj RR, Mancini A, Ballarini P, Castelli M, Schrallhammer, et al (2015) Microbial consortium associated with the Antarctic marine ciliate Euplotes focardii: an investigation from genomic sequences. Microbial Ecol 70:484-497

52. Valbonesi A, Luporini P (1993) Biology of Euplotes focardii an Antarctic ciliate. Polar Biol 13:489-493

53. Di Giuseppe G, Dini F, Vallesi A, Luporini P (2015) Genetic relationships in bipolar species of the protist ciliate Euplotes. Hydrobiologia 761:71-83

54. Ahlinder J, Ohrman C, Svensson K, Lindgren P, Johansson A, Forsman M, et al (2012) Increased knowledge of Francisella genus diversity highlights the benefits of optimised DNA-based assays. BMC Microbiol 12:220

55. Moran NA, Plague GR (2004) Genomic changes following host restriction in bacteria. Curr Opin Genet Dev 14:627-633

56. Dutta C, Paul S (2012) Microbial lifestyle and genome signatures. Cur genomics 13: 153-162

57. Brodmann M, Dreier RF, Broz P, Basler M (2017) Francisella requires dynamic type VI secretion system and $\mathrm{ClpB}$ to deliver effectors for phagosomal escape. Nat Commun 8:15853

58. Checroun C, Wehrly TD, Fischer ER, Hayes SF, Celli J (2006) Autophagy-mediated reentry of Francisella tularensis into the endocytic compartment after cytoplasmic replication. Proc Natl Acad Sci USA 103:14578-14583

\section{Figure legends}

Fig $1 F$. adeliensis identification. A Schematic representation of the $F$. adeliensis rDNA operon. The relative positions of fluorescent FISH probes and primers used in colony-PCR are indicated. The 33-bp sequence exclusive of F. adeliensis rDNA operon is shown. B Fluorescent in situ hybridization of E. petzi cells: a, signal from fluorescein-labeled probe EUB338 for all eubacteria; b, signal from Cy3-labeled probe Bwall1448 specific for Francisella; c, co-localization of signals of the two labeled probes. Scale bar=20 $\mu \mathrm{m}$. 
480 Fig 2 Transmission electron microscopy of $E$. petzi cells containing F. adeliensis. A, B Micrographs of $E$.

481 petzi thin sections showing bacteria individually dispersed in the host cytoplasm, or associated together in

482 groups enclosed in membrane-bound compartments. C-G Panels showing magnifications of the boxed areas

483 in panels A and B. Abbreviations: MAC, macronucleus; AZM, adoral zone membranelles.

484

485 Fig $3 F$. adeliensis growth. A Dot-plate analysis of $F$. adeliensis on CHAB agar. Serial dilutions of a $F$.

486 adeliensis cell suspension were spotted on plates and the plates incubated at the indicated temperatures for

487 the indicated times (days). B Growth curves of $F$. adeliensis in liquid medium incubated at the indicated

488 temperatures. Data from a representative experiment are shown; experiments were repeated three times with 489 equivalent results.

490

491 Fig 4 Evolutionary relationships of $F$. adeliensis. The optimal tree with the sum of branch length =

492284909.68814135 is shown. The tree is drawn to scale, with branch lengths in the same units as those of the 493 evolutionary distances used to infer the phylogenetic tree. The scale bar corresponds to 5000 nucleotide 494 differences. Growth style and environment of each species are indicated by colored dots on the right; the six 495 major branches of the tree are enclosed in colored rectangles. The position of $F$. adeliensis is highlighted in 496 bold.

497 
Table 1. Genome comparison of ten different Francisella species. The accession numbers of the examined genomes are indicated.

\begin{tabular}{|c|c|c|c|c|c|c|}
\hline Species & Origin & $\begin{array}{l}\text { Genome } \\
\text { size (bp) }\end{array}$ & $\begin{array}{l}\text { Pred. } \\
\text { proteins }\end{array}$ & tRNAs & $\begin{array}{c}\text { rRNA } \\
(16 S+23 S) \\
\end{array}$ & $\% \mathbf{G}+\mathbf{C}$ \\
\hline $\begin{array}{l}\text { F. adeliensis } \\
\text { CP021781 }\end{array}$ & E. petzi & $2,054,094$ & 1,880 & 38 & $\begin{array}{c}10 \\
3+3\end{array}$ & 32.6 \\
\hline $\begin{array}{l}\text { F. endociliophora } \\
\text { NZ_CP009574 }\end{array}$ & E. raikovi & $2,015,987$ & 1,891 & 38 & $\begin{array}{c}10 \\
3+3\end{array}$ & 32.4 \\
\hline $\begin{array}{c}\text { Allofrancisella guangzhouensis } \\
\text { NZ_CP010427.1 }\end{array}$ & $\begin{array}{l}\text { cooling tower } \\
\text { water }\end{array}$ & $1,658,482$ & 1,423 & 38 & $\begin{array}{c}10 \\
3+3\end{array}$ & 32.0 \\
\hline $\begin{array}{c}\text { F. noatunensis subsp. orientalis } \\
\text { FNO24 } \\
\text { NZ_CP011922.1 }\end{array}$ & Nile tilapia & $1,862,322$ & 1,449 & 39 & $\begin{array}{c}10 \\
3+3\end{array}$ & 32.3 \\
\hline $\begin{array}{c}\text { F. philomiragia GA01-2794 } \\
\text { NZ_CP009440.1 }\end{array}$ & human & $2,148,038$ & 1,999 & 40 & $\begin{array}{c}10 \\
3+3\end{array}$ & 32.4 \\
\hline $\begin{array}{l}\text { F. hispaniensis } 3523 \\
\quad \text { NC_017449 }\end{array}$ & human & $1,945,310$ & 1,798 & 38 & $\begin{array}{c}10 \\
3+3\end{array}$ & 32.3 \\
\hline $\begin{array}{c}\text { F. tularensis subsp. holarctica } \\
\text { LVS } \\
\text { NC_007880 }\end{array}$ & vaccine strain & $1,895,994$ & 1,766 & 38 & $\begin{array}{c}10 \\
3+3\end{array}$ & 32.2 \\
\hline $\begin{array}{c}\text { F.tularensis subsp.tularensis } \\
\text { WY96 } \\
\text { NZ_CP012037.1 }\end{array}$ & human & $2,005,074$ & 1,871 & 38 & $\begin{array}{c}10 \\
3+3\end{array}$ & 32.4 \\
\hline $\begin{array}{l}\text { F. tularensis subsp. } \\
\text { mediasiatica FSC147 } \\
\text { NC_010677 }\end{array}$ & gerbil & $1,893,886$ & 1,659 & 38 & $\begin{array}{c}10 \\
3+3\end{array}$ & 32.3 \\
\hline $\begin{array}{l}\text { F. salina TX077308 } \\
\text { NC_015696 }\end{array}$ & seawater & $2,035,931$ & 1,884 & 39 & $\begin{array}{c}10 \\
3+3\end{array}$ & 32.9 \\
\hline
\end{tabular}


Table 2. ANI in percent between known Francisella genomes.

\begin{tabular}{|c|c|c|c|c|c|}
\hline & $\begin{array}{c}\text { F.endociliophora } \\
\text { NZ_CP009574.1 }\end{array}$ & $\begin{array}{l}\text { A. guangzhouensis } \\
\text { NZ_CP010427.1 }\end{array}$ & $\begin{array}{c}\text { F.noatunensis } \\
\text { subsp. orientalis } \\
\text { FNO24 } \\
\text { NZ_CP011922.1 }\end{array}$ & $\begin{array}{c}\text { F. philomiragia } \\
\text { GA01-2794 } \\
\text { NZ_CP009440.1 }\end{array}$ & $\begin{array}{c}\text { F. tularensis subsp. } \\
\text { tularensis WY96 } \\
\text { NZ_CP012037.1 }\end{array}$ \\
\hline $\begin{array}{l}\text { F. adeliensis } \\
\text { CP021781 }\end{array}$ & 78.84 & 77.07 & 77.58 & 77.89 & 77.69 \\
\hline $\begin{array}{l}\text { F. endociliophora } \\
\text { NZ_CP009574.1 }\end{array}$ & - & 78.4 & 80.44 & 81.51 & 80.22 \\
\hline $\begin{array}{l}\text { A. guangzhouensis } \\
\text { NZ_CP010427.1 }\end{array}$ & - & - & 79.30 & 78.5 & 78.99 \\
\hline $\begin{array}{l}\text { F. noatunensis subsp. } \\
\text { orientalis FNO24 } \\
\text { NZ_CP011922.1 }\end{array}$ & - & - & - & 95.15 & 82.09 \\
\hline $\begin{array}{c}\text { F. philomiragia GA01-2794 } \\
\text { NZ_CP009440.1 }\end{array}$ & - & - & - & - & 82.39 \\
\hline
\end{tabular}


A

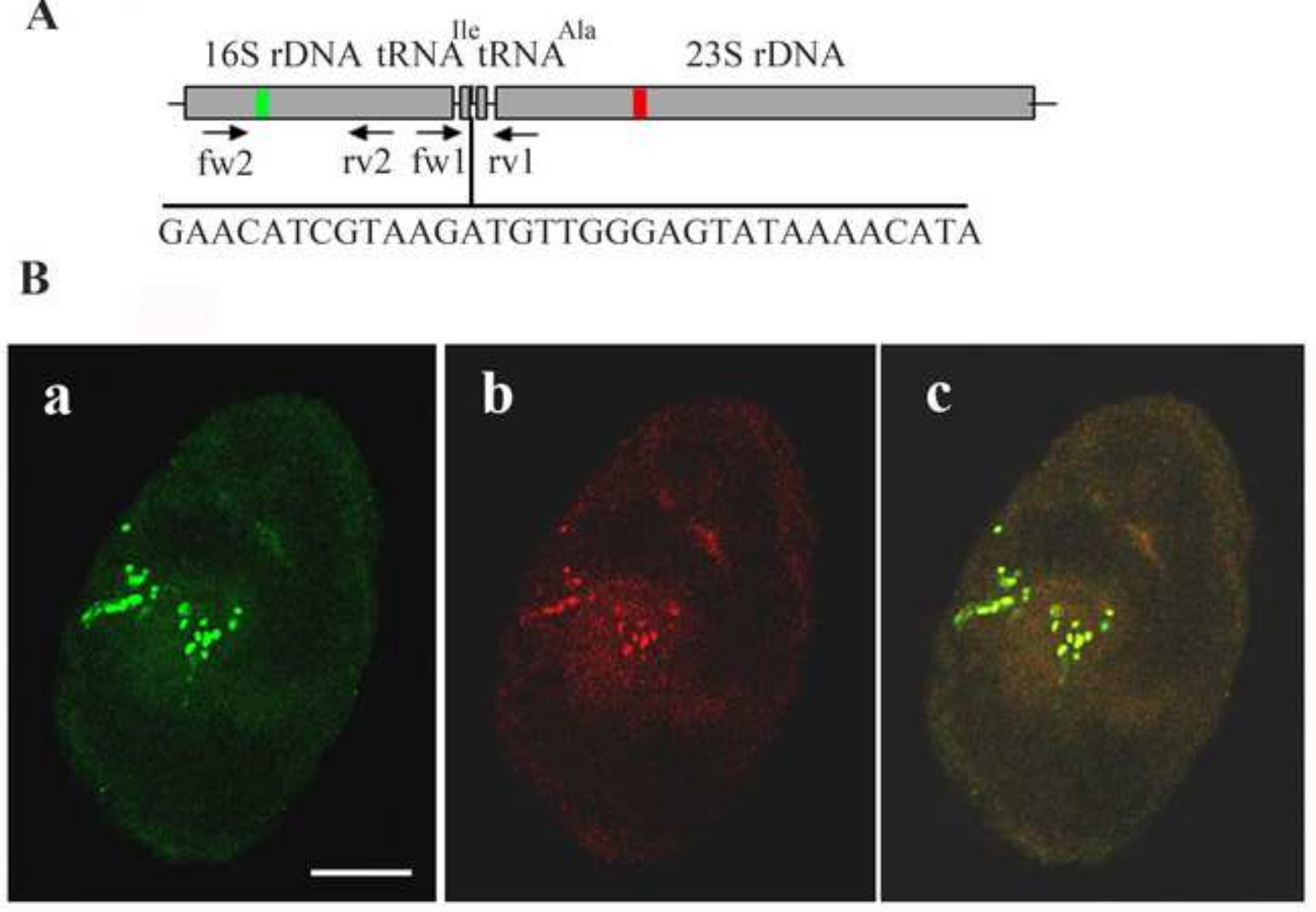




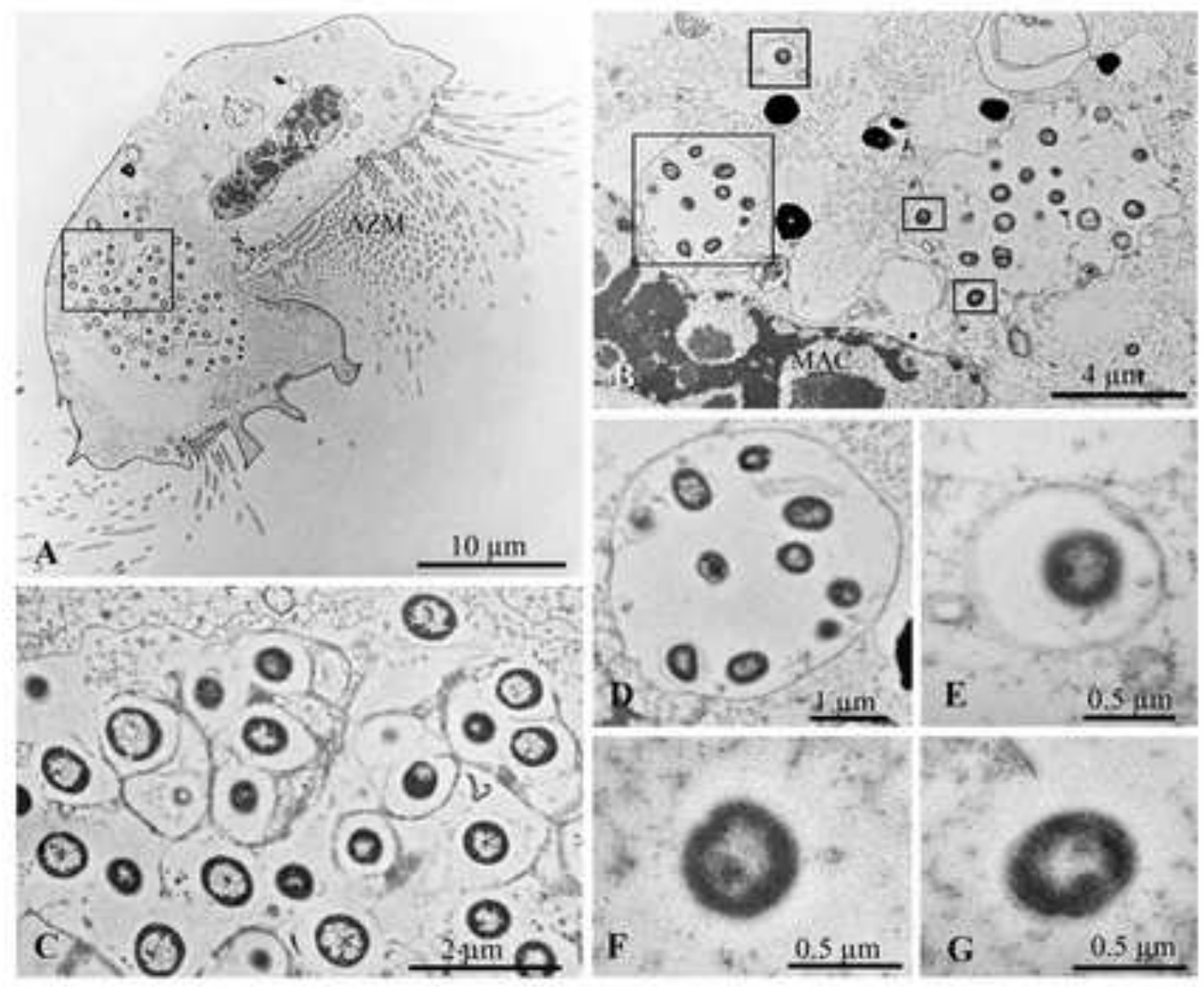



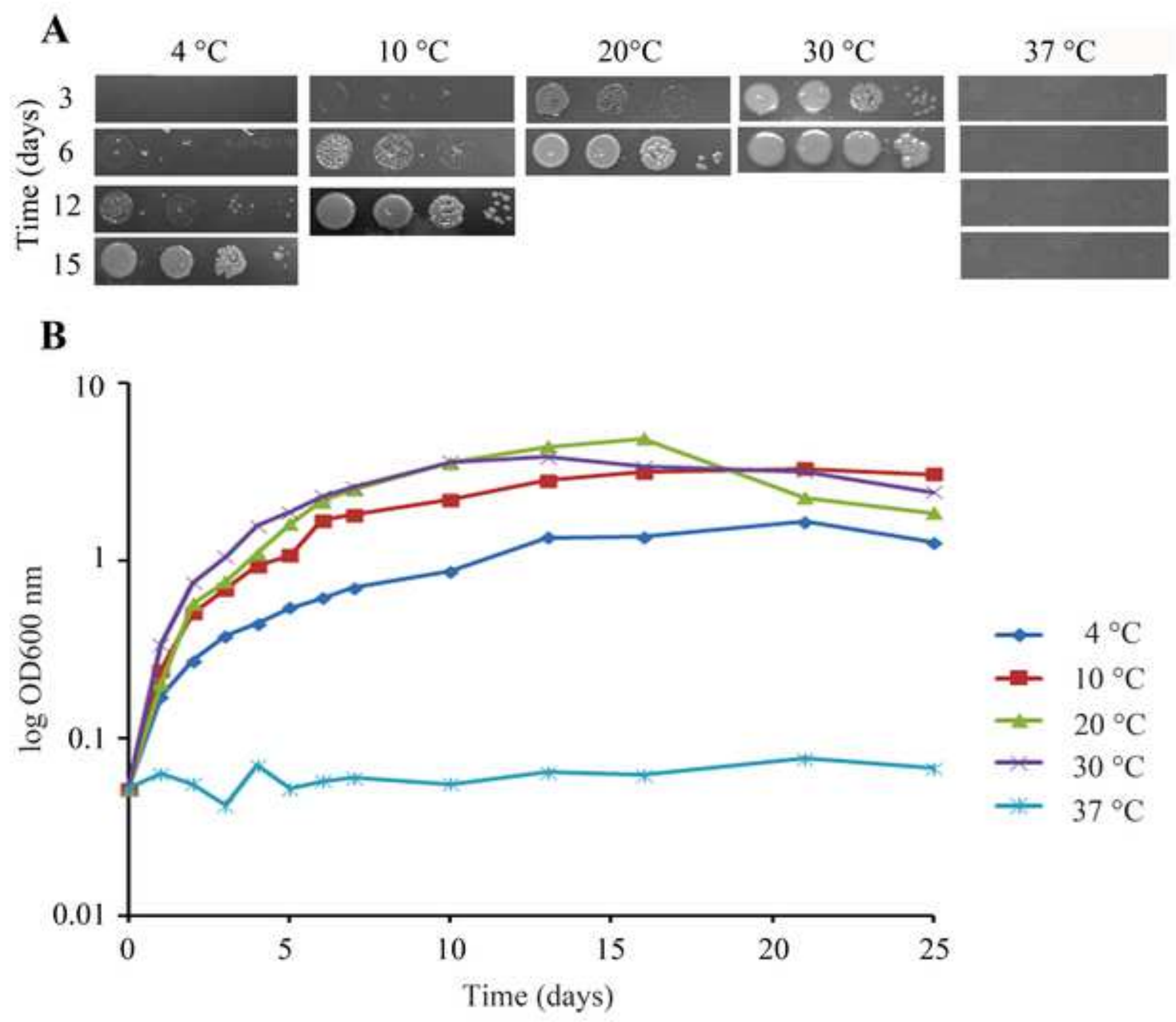
Growth style:

- Euplotes-associated

animal-associated

- supposed free-living

Environment:

soil

freshwater

marine, or brackish

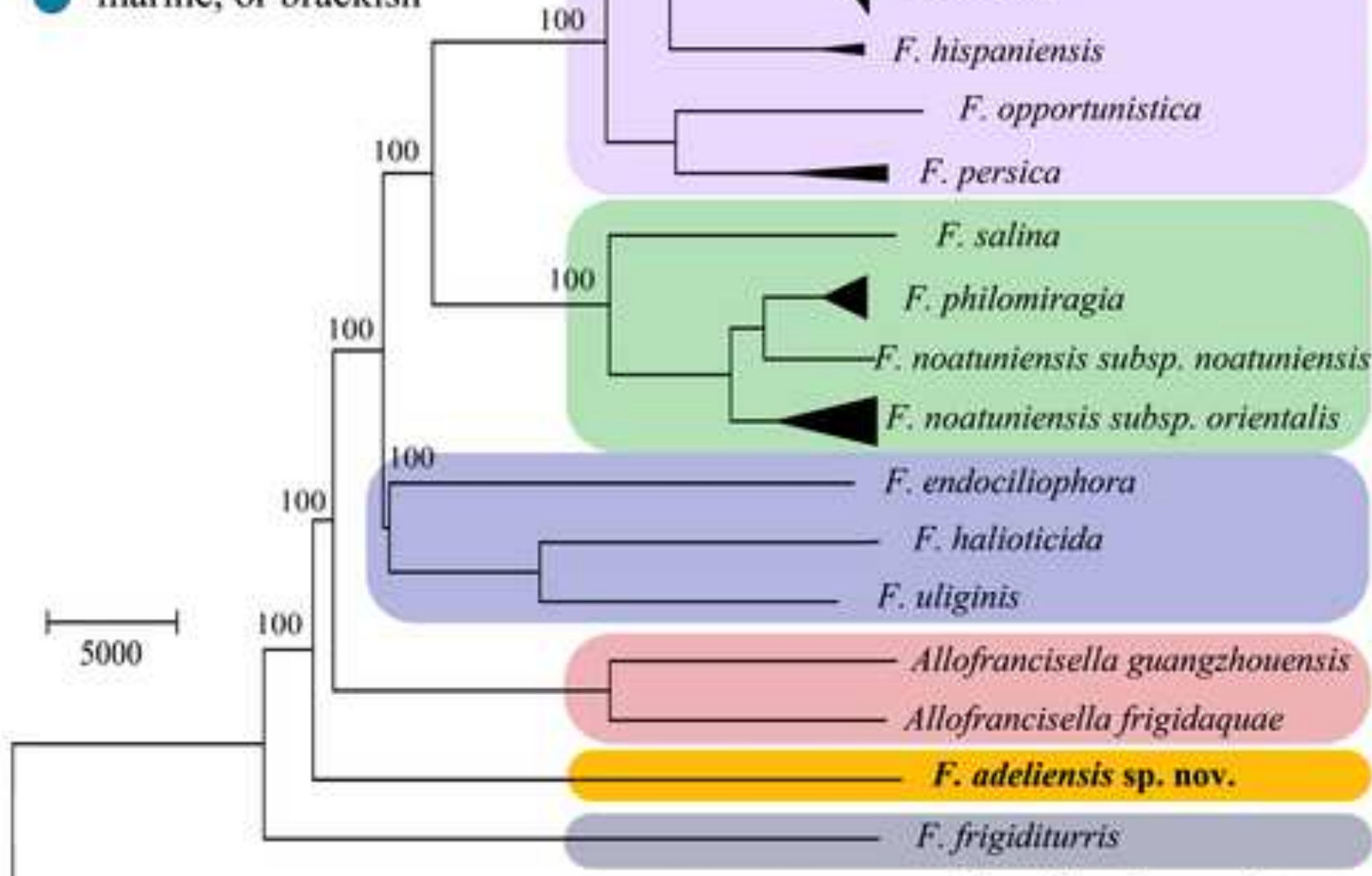

F. tulariensis

F. novicida

F. hispaniensis

F. opportunistica

persica
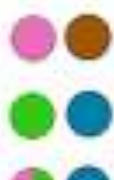

10

0

0

0

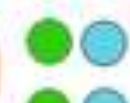

00

0

Fangia hongkongensis 